\title{
ANALISIS KONSISTENSI MATRIKS KEPUTUSAN : SUATU PERBANDINGAN NUMERIK
}

\author{
Farikhin \\ Departemen Matematika FSM UNDIP \\ farikhin.math.undip@gmail.com
}

\begin{abstract}
In this paper, we study some algorithms to improve consistency of resiprocal pairwise matrix. The algorithm is proposed by using relationship with multiplicative preference relation and fuzzy preference relation. An example is presented to evaluate these algorithms.
\end{abstract}

Keywords: resiprocal pairwise matrix, multiplicative preference relation, fuzzy preference relation, and consistency.

\begin{abstract}
ABSTRAK. Dalam makalah ini, dibahas beberapa algoritma untuk memperbaiki nilai konsistensi matriks keputusan. Suatu algoritma diusulkan dengan menggunakan hubungan antara relasi preferensi multiplikatif dan relasi preferensi fuzzy, Satu contoh diberikan untuk mengevaluasi algoritma-algoritma tersebut.
\end{abstract}

Kata Kunci: matriks keputusan, relasi preferensi multiplikatif, relasi preferensi fuzzy, dan nilai konsistensi.

\section{PENDAHULUAN}

Perencanaan dan evaluasi adalah kegiatan yang sering dilakukan. Kedua kegiatan tersebut memerlukan beberapa pertimbangan agar mendapatkan hasil yang optimal. Metode AHP (analytic hierarchy process) adalah salah satu metode yang sering digunakan untuk aktivitas perencanaan dan evaluasi. Metode ini dibuat dalam beberapa tahap, yakni tahap penyusunan hirarki masalah, tahap pembentukan matriks keputusan, tahap pengujian nilai konsistensi, dan tahap penentuan prioritas alternatif keputusan menggunakan vektor prioritas. Ada beberapa problem matematis dalam metode AHP, yaitu problema konsistensi dan problema penentuan vektor prioritas. Metode AHP dikatakan dapat diterima jika nilai konsistensinya kurang dari atau sama dengan sepersepuluh (Saaty dan Vargas, 2012). Dalam makalah ini, dikaji perbaikan nilai konsistensi dengan beberapa pendekatan. 
Perbaikan nilai konsistensi matriks keputusan dapat dilakukan melalui analisis elemen dalam matriks keputusan dan kaitannya dengan vektor prioritas yang akan dihasilkan. Kajian ini berdasar pada syarat cukup dan syarat perlu matriks keputusan yang konsisten adalah nilai eigen maksimalnya sama dengan $n$, dengan $n$ menyatakan jumlah baris/kolom matriks keputusan. Berdasarkan hal ini, beberapa algoritma dihasilkan. Xu dan Cuiping (1999) mengusulkan suatu algoritma berdasarkan nilai eigen maksimal yang mendekati $n$. Pendekatan yang lain juga dapat dikerjakan melalui transformasi logaritmis yang menghasilkan problema optimasi. Problem tersebut diselesaikan menggunakan metode Lagrange (Koczkodajdan Orlowski, 1999). Matriks keputusan dapat ditinjau sebagai suatu matriks yang elemen-elemennya merupakan hasil dari relasi tertentu. Relasi yang dimaksud adalah relasi preferensi multiplikatif. Relasi preferensi ini berkaitan dengan relasi preferensi fuzzy. Secara khusus, sifat konsisten dalam relasi preferensi multiplikatif terkait dengan sifat konsisten aditif dalam relasi preferensi fuzzy. Kajian mengenai hal ini dibahas secara mendalam pada (Xu dan Da, 2003; Herrera dkk., 2004; Fedrizzidan Brunelli, 2010; Tanino, 1984)

Dalam makalah ini, dikaji algoritma dari Xu dan Cuiping (1999) serta Koczkodaj dan Orlowski (1999). Selain itu, diusulkan algoritma untuk perbaikan nilai konsistensi melalui hubungan sifat konsistensi dan sifat konsistensi aditif. Dengan transformasi tertentu, sifat konsisten dalam relasi preferensi multiplikatif berakibat konsisten aditif. Hal ini juga berlaku sebaliknya. Tinjauan ini yang menjadi dasar menyusunan algoritma yang dihasilkan. Sebagai evaluasinya, dibahas suatu contoh penggunaan algortima yang dihasilkan. Selanjutnya, hasil ini dibandingkan dengan beberapa metode lain yang dapat memperbaiki nilai konsistensi matriks keputusan.

\section{METODE PENELITIAN}

Dalam bagian ini, dibahas pendekatan analitik pada dua relasi preferensi. Relasi yang dimaksud adalah relasi preferensi multiplikatif dan relasi preferensi fuzzy. Pendekatan selanjutnya adalah kajian numerik melalui penyusuan 
algoritma untuk meningkatkan nilai konsistensi. Algoritma ini disusun berdasarkan hubungan antara sifat konsisten dan konsisten aditif.

\subsection{Dua Relasi Preferensi}

Pada bagian ini, dibahas secara ringkas hubungan relasi preferensi yang bersifat konsisten dan konsisten aditif. Selanjutnya, dibahas beberapa algoritma yang digunakan untuk memperbaiki nilai konsistensi matriks keputusan.

Diberikan himpunan alternatif keputusan $A=\left\{A_{1}, A_{2}, \ldots, A_{n}\right\}$, dan notasi $a_{i, j}$ menyatakan nilai preferensi alternatif keputusan $A_{i}$ terhadap alternatif keputusan $A_{j}$, untuk $i, j=1,2,3, \ldots, n$. Jika nilai-nilai $a_{i, j}$ disajikan dalam matriks

$$
A=\left[\begin{array}{cccc}
a_{1,1} & a_{1,2} & \ldots & a_{1, n} \\
a_{2,1} & a_{2,2} & \ldots & a_{2, n} \\
\vdots & \vdots & \ddots & \vdots \\
a_{n, 1} & a_{n, 2} & \ldots & a_{n, n}
\end{array}\right]
$$

dengan $a_{i, j} \geq 0$ untuk $i, j=1,2,3, \ldots, n$. Untuk selanjutnya, matriks $A$ dinamakan matriks keputusan. Berdasarkan matriks $A$ didefinisikan pengertian-perngertian berikut.

Definisi 1 (Saaty, 1986).Diberikan matriks keputusan

$$
A=\left[\begin{array}{cccc}
a_{1,1} & a_{1,2} & \ldots & a_{1, n} \\
a_{2,1} & a_{2,2} & \ldots & a_{2, n} \\
\vdots & \vdots & \ddots & \vdots \\
a_{n, 1} & a_{n, 2} & \ldots & a_{n, n}
\end{array}\right] .
$$

- Matriks A disebut matriks relasi preferensi multiplikatif (matriks RPM) jika $a_{i, j}>0, a_{i, i}=1$, dan $a_{i, j} \times a_{j, i}=1$ untuk $i, j=1,2,3, \ldots, n$.

- Matriks RPM A dikatakan konsisten $j i k a a_{i, j} \times a_{j, k}=a_{i, k}$ untuk setiapi, $j, k=$ $1,2, \ldots, n$.

Saaty memberikan syarat cukup dan perlu agar matriks RPM bersifat konsisten melalui nilai eigen maksimal. Jika $\mu_{A}$ nilai eigen maksimal matriks matriks RPM $A$, matriks $A$ konsisten jika dan hanya jika $\mu_{A}=n$, dengan $n$ jumlah baris matriks $A$ (Saaty, 1986). 
Definisi 2 (Tanino, 1984).Diberikan matriks keputusan

$$
A=\left[\begin{array}{cccc}
a_{1,1} & a_{1,2} & \ldots & a_{1, n} \\
a_{2,1} & a_{2,2} & \ldots & a_{2, n} \\
\vdots & \vdots & \ddots & \vdots \\
a_{n, 1} & a_{n, 2} & \ldots & a_{n, n}
\end{array}\right] .
$$

- Matriks A disebut matriks relasi preferensi fuzzy (matriks $\mathbf{R P F}$ ) jika $a_{i, j}>0$, $a_{i, i}=0,5$, dan $a_{i, j}+a_{j, i}=1$ untuk $i, j=1,2,3, \ldots, n$.

- Matriks RPM A dikatakan konsisten aditif jikaa $a_{i, j}+a_{j, k}+a_{k, i}=\frac{3}{2} u n t u k$ setiapi, $j, k=1,2, \ldots, n$.

Teorema berikut menjelaskan syarat cukup dan syarat perlu agar matriks RPF bersifat konsistens aditif. Untuk pembuktian teorema ini dapat dilihat dalam (Herrera dkk., 2004).

Teorema 1 (Herrera dkk., 2004).Diberikan matriks RPF

$$
A=\left[\begin{array}{cccc}
a_{1,1} & a_{1,2} & \ldots & a_{1, n} \\
a_{2,1} & a_{2,2} & \ldots & a_{2, n} \\
\vdots & \vdots & \ddots & \vdots \\
a_{n, 1} & a_{n, 2} & \ldots & a_{n, n}
\end{array}\right] .
$$

Pernyataan-pernyataan berikut adalah ekuivalen.

(a) A konsisten aditif

(b) $a_{i, j}+a_{j, k}+a_{k, i}=\frac{3}{2}$ untuk setiap $i<j<k$

(c) $a_{i, j}+a_{j, k}+a_{i, k}=\frac{3}{2}$ untuk setiap $i \leq j \leq k$

(d) $a_{i,(i+1)}+a_{(i+1),(i+2)}+\cdots+a_{(j-1), j}+a_{j, i}=\frac{j-i+1}{2}$ untuk $i<j$.

Dua teorema berikut memperlihatkan hubungan antara matriks RPM dan matriks RPF.

Teorema 2 (Xu dan Da, 2003).Jika

$$
A=\left[\begin{array}{cccc}
1 & a_{1,2} & \ldots & a_{1, n} \\
a_{2,1} & 1 & \ldots & a_{2, n} \\
\vdots & \vdots & \ddots & \vdots \\
a_{n, 1} & a_{n, 2} & \ldots & 1
\end{array}\right]
$$


matriks RPM, makamatriks

$$
R=\left[\begin{array}{cccc}
r_{1,1} & r_{1,2} & \ldots & r_{1, n} \\
r_{2,1} & r_{2,2} & \ldots & r \\
\vdots & \vdots & \ddots & \vdots \\
r_{n, 1} & r_{n, 2} & \ldots & r_{n, n}
\end{array}\right]
$$

merupakanmatriks $R P F$, dengan

$$
r_{i, j}=\frac{a_{i, j}}{1+a_{i, j}}=\frac{1}{1+a_{j, i}}
$$

untuk $i, j=1,2, \ldots, n$.

Teorema 3 (Xu dan Da, 2003).Jika

$$
R=\left[\begin{array}{cccc}
r_{1,1} & r_{1,2} & \ldots & r_{1, n} \\
r_{2,1} & r_{2,2} & \ldots & r \\
\vdots & \vdots & \ddots & \vdots \\
r_{n, 1} & r_{n, 2} & \ldots & r_{n, n}
\end{array}\right]
$$

matriks RPF, maka

$$
A=\left[\begin{array}{cccc}
1 & a_{1,2} & \ldots & a_{1, n} \\
a_{2,1} & 1 & \ldots & a_{2, n} \\
\vdots & \vdots & \ddots & \vdots \\
a_{n, 1} & a_{n, 2} & \ldots & 1
\end{array}\right]
$$

merupakanmatriks $R P M$, dengan

$$
a_{i, j}=9^{2\left(r_{i, j}-0,5\right)}
$$

untuk $i, j=1,2, \ldots, n$.

Teorema 4 (Xu dan Da, 2003; Herrera dkk., 2004).Diberikan matriks RPM

$$
A=\left[\begin{array}{cccc}
1 & a_{1,2} & \ldots & a_{1, n} \\
a_{2,1} & 1 & \ldots & a_{2, n} \\
\vdots & \vdots & \ddots & \vdots \\
a_{n, 1} & a_{n, 2} & \ldots & 1
\end{array}\right]
$$

dan

$$
R=\left[\begin{array}{cccc}
r_{1,1} & r_{1,2} & \ldots & r_{1, n} \\
r_{2,1} & r_{2,2} & \ldots & r \\
\vdots & \vdots & \ddots & \vdots \\
r_{n, 1} & r_{n, 2} & \ldots & r_{n, n}
\end{array}\right]
$$


dengan $r_{i, j}=\frac{a_{i, j}}{1+a_{i, j}}=\frac{1}{1+a_{j, i}}$ untuk $i, j=1,2, \ldots$, n.Jika matriks RPM A bersifat konsisten maka matriks $R$ merupakan matriks $R P F$ yang konsisten aditif.

Teorema 5 (Xu dan Da, 2003; Herrera dkk., 2004).Diberikan matriks RPF

$$
R=\left[\begin{array}{cccc}
r_{1,1} & r_{1,2} & \ldots & r_{1, n} \\
r_{2,1} & r_{2,2} & \ldots & r \\
\vdots & \vdots & \ddots & \vdots \\
r_{n, 1} & r_{n, 2} & \ldots & r_{n, n}
\end{array}\right]
$$

dan

$$
A=\left[\begin{array}{cccc}
1 & a_{1,2} & \ldots & a_{1, n} \\
a_{2,1} & 1 & \ldots & a_{2, n} \\
\vdots & \vdots & \ddots & \vdots \\
a_{n, 1} & a_{n, 2} & \ldots & 1
\end{array}\right]
$$

dengan $a_{i, j}=9^{2\left(r_{i, j}-0,5\right)}$ untuk $i, j=1,2, \ldots$, n.Jika matriks $R P F \quad R$ bersifat konsisten aditif maka matriks A merupakan matriks RPM yang konsisten.

Teorema 4 dan Teorema 5 memberikan jaminan sifat konsisten dari sifat konsisten aditif, juga sebaliknya. Dengan transformasi seperti dalam Teorema 2 dan Teorema 3, sifat konsisten berhubungan erat dengan sifat konsisten aditif. Teorema berikut memperlihatkan syarat cukup dan syarat perlu matriks RPF menjadi matriks RPF yang konsisten aditif.

Teorema 6 (Siti Khabibah dkk., 2015). Diberikan matriks RPF

$$
F=\left[\begin{array}{cccc}
F_{1,1} & F_{1,2} & \ldots & F_{1, n} \\
F_{2,1} & F_{2,2} & \ldots & F_{2, n} \\
\vdots & \vdots & \ddots & \vdots \\
F_{n, 1} & F_{n, 2} & \ldots & F_{n, n}
\end{array}\right]
$$

dan

$$
G=\left[\begin{array}{cccc}
G_{1,1} & G_{1,2} & \ldots & G_{1, n} \\
G_{2,1} & G_{2,2} & \ldots & G_{2, n} \\
\vdots & \vdots & \ddots & \vdots \\
G_{n, 1} & G_{n, 2} & \ldots & G_{n, n}
\end{array}\right]
$$

dengan 


$$
G_{i, j}=\frac{1}{n}\left(\sum_{k=1}^{n}\left(F_{i, k}+F_{k, j}\right)\right)-\frac{1}{2}
$$

untuk setiap $1 \leq i, j \leq n$. Matriks RPF F mempunyai sifat konsisten aditif jika dan hanya jika $F=G$.

\subsection{Nilai Konsistensi}

Pada bagian ini, dibahas beberapa algoritma untuk meningkatkan nilai konsistensi matriks keputusan. Sebelumnya, dibahas secara ringkas pengertian nilai konsistensi dan hal-hal yang terkait dengannya.

Nilai konsistensi mencerminkan adanya konsisten pembuat keputusan. Pengukuran konsistensi pembuat keputusan untuk menentukan keputusan yang dipilih, dapat dilakukan melalui analisis elemen-elemen matriks keputusan $A$. Kuantitas

$$
C I=\frac{\lambda_{A}-n}{n-1}
$$

diinterpretasikan sebagai rata-rata ketidakpastian yang dihasilkan oleh pembuat keputusan (Saaty, 1986). Rasio konsistensi dihitung menggunakan rumus

$$
C R=\frac{C I}{I R}
$$

dengan $I R$ ditentukan dalam tabel berikut.

Tabel 1.Nilai $I R$ untuk $n$ alternatif keputusan

\begin{tabular}{|c|l|l|l|l|}
\hline $\mathrm{n}$ & 3 & 4 & 5 & 6 \\
\hline $\mathrm{IR}$ & 0,58 & 0,90 & 1,12 & 1,24 \\
\hline $\mathrm{n}$ & 7 & 8 & 9 & 10 \\
\hline $\mathrm{IR}$ & 1,32 & 1,41 & 1,45 & 1,49 \\
\hline
\end{tabular}

Matriks RPM $A$ dikatakan dapat diterima (konsisten secara numerik) jika nilai CR kurang dari atau sama dengan 0,1 .

$\mathrm{Xu}$ dan Cuiping mengusulkan suatu algoritma perbaikan nilai konsistensi melalui bentuk tranformasi 


$$
a_{i, j}^{*}=a_{i, j}^{\delta}\left(\frac{w_{i}}{w_{j}}\right)^{1-\delta}
$$

dengan $0<\delta<1, \bar{w}=\left(w_{1}, w_{2}, \ldots, w_{n}\right)$ vektor eigen yang terkait dengan $\lambda_{A}$, untuk $i, j=1,2, \ldots, n$. Nilai eigen maksimal matriks $A^{*}=\left[a_{i, j}^{*}\right]$ lebih kecil daripada nilai eigen maksimal matriks $A$. Berdasarkan ini, dibuat algoritma peningkatan nilai konsistensi sebagai berikut.

Algoritma 1 (Xu\& Cuiping, 1999)

Input : Matriks RPM $A=\left[a_{i, j}\right]$

$m=$ jumlah iterasi

$$
0<\delta<1
$$

Output : matriks $\mathrm{RPM} A^{(m)}$ yang dapat diterima.

Step 1. Tentukan $A^{(k)}=A$ untuk $k=0$

Step 2. Hitung $\lambda_{A^{(k)}}$ dan vektor eigennya $\bar{w}^{(k)}=\left(w_{1}^{(k)}, w_{2}^{(k)}, \ldots, w_{n}^{(k)}\right)$

Step 3. Hitung $C I=\frac{\lambda_{A^{(k)}}-n}{n-1}$ dan $C R=\frac{C I}{I R}$.

Step 4. Jika $R K \leq 0,1$, kerjakan step 7. jika tidak, kerjakan step berikut

Step 5. Buat matriks RPM baru $A^{(k+1)}=\left[a_{i, j}^{(k+1)}\right]$ dengan

$$
a_{i, j}^{(k+1)}=\left(a_{i, j}^{(k)}\right)^{\delta}\left(\frac{w_{i}^{(k)}}{w_{j}^{(k)}}\right)^{1-\delta}
$$

Step 6. Pilih $k=k+1$ dan kembali ke step 2 .

Step 7. Pilih $A^{(m)}=A^{(k)}$ dan $\bar{w}^{(k)}$ sebagai vektor prioritasnya.

Step 8. Selesai.•

Koczkodaj dan Orlowski mengusulkan algoritma perbaikan nilai konsistensi melalui hubungan elemen-elemen matriks keputusan dalam satu baris/kolom yang sama. Algoritma tersebut dituliskan sebagai berikut.

Algoritma 2 (Koczkodaj \& Orlowski, 1999)

Input : matriks $\operatorname{RPM} A=\left[a_{i, j}\right]$

Output : matriks RPM $B=\left[b_{i, j}\right]$ yang konsisten

Step 1. Hitung matriks $D=\left[d_{i, j}\right]$ dengan $d_{i, j}=\log \left(a_{i, j}\right)$

Step 2. Hitung vektor $E=\left(e_{1}, e_{2}, \ldots, e_{n}\right)$ dengan $e_{k}=\sum_{j=1}^{n} d_{k, j}$

Setp 3. Hitung vektor $H=\left(h_{1}, h_{2}, \ldots, h_{n}\right)$ dengan $h_{k}=\sum_{j=1}^{n} d_{j, k}$

Step 4. Konstruksikan matriks $M=\left[m_{i, j}\right]$ dengan 


$$
m_{i, j}=\frac{1}{2 n}\left(\left(e_{i}-e_{j}\right)+\left(h_{j}-h_{i}\right)\right)
$$

Step 5. Konstruksikan matriks $B=\left[b_{i, j}\right]$ dengan $b_{i, j}=\exp \left(m_{i, j}\right)$ Step 6. Selesai.

Mengingat Teorema 6, penulis mengusulkan algoritma perbaikan nilai konsistensi melalui matriks RPF. Matriks RPM ditarnsformasikan ke bentuk matriks RPF. Hasil transformasi ini dan menginggat Teorema 6, dapat dikontruksikan matriks RPF yang konsisten aditif. Dengan menggunakan Teorema 5, diperoleh bentuk matriks RPM yang konsisten. Adapun algoritma yang diusulkan ditulis sebagai berikut.

\section{Algoritma 3}

Input : matriks $\operatorname{RPM} A=\left[a_{i, j}\right]$

Output : matriks RPM $B=\left[b_{i, j}\right]$ yang konsisten

Step 1. Kontruksikan matriks $F=\left[f_{i, j}\right]$ dengan $f_{i, j}=\frac{a_{i, j}}{1+a_{i, j}}$

Step 2. Kontruksikan matriks $G=\left[g_{i, j}\right]$ dengan $g_{i, j}=\frac{1}{n}\left(\sum_{k=1}^{n}\left(f_{i, k}+f_{k, j}\right)\right)-\frac{1}{2}$

Setp 3. Jika terdapat $g_{i, j}<0$, maka kontruksikan matriks $U=\left[u_{i, j}\right]$ dengan

dan $x=\sup \left\{\left|g_{i, j}\right| / g_{i, j}<0\right\}$.

$$
u_{i, j}=\frac{g_{i, j}+x}{1+2 x}
$$

Jika tidak demikian, kerjakan step 4

Step 4. Konstruksikan matriks $B=\left[b_{i, j}\right]$ dengan $b_{i, j}=9^{2\left(g_{i, j}-0,5\right)}$

Step 5. Selesai.

\section{CONTOH DAN PEMBAHASAN}

Pada bagian ini, dberikan suatu contoh penggunaan tiga algoritma yang dijelaskan pada bagian sebelumnya. Contoh matriks keputusan diambil dari (Xu dan Cuiping, 1999). Diberikan matriks keputusan

$$
A=\left[\begin{array}{ccc}
1 & 7 & 1 / 5 \\
1 / 7 & 1 & 1 / 8 \\
1 / 5 & 8 & 1
\end{array}\right]
$$

Matriks keputusan $A$ tidak konsisten, sebab $\lambda_{A}=3,247>n=3$. Jika Algoritma 1 dikerjakan pada matriks $A$, dengan $\delta=0,1$ maka nilai eigen maksimalnya sama dengan 3,002 (Xu \& Cuiping, 1999). 
Tabel 1 menunjukkan perbandingan nilai eigen maksimal dan vektor eigennya yang dihasilkan oleh tiga algoritma tersebut. Algoritma 2 dan 3 menghasilkan nilai eigen maksimal yang hampir sama dengan tiga. Hal ini menunjukkan bahwa dua algoritma ini dapat meningkatkan nilai konsisten matriks keputusan.

Algoritma 1 juga memberikan hasil perbaikan nilai konsistensi. Untuk komputasinya, Algoritma 1 memerlukan input $\delta$ yang berupa paramter. Hal ini berarti pemilihan nilai $\delta$ yang mengoptimalkan nilai eigen maksimal akan menjadi problem tersendiri. Oleh karenanya, algoritma ini baik secara analitik tetapi kurang efisien dari aspek komputasinya.

Algoritma 2 memberikan hasil yang sama dengan algoritma 3. Secara analitik, algoritma 2 disusun sebagai hasil dari problem optimasi. Seperti diketahui, suatu matriks keputusan bersifat konsisten jika nilai elemen $a_{i, j}$ merupakan perbandingan antara bobot keputusan ke $-i$ dengan bobot keputusan ke- $j$. Hanya saja, algoritma 3 ini mengasumsikan bahwa trasnformasi logaritmis sedekat mungkin dengan elemen-elemen dalam vektor prioritas.

Tabel 2. Perbandingan nilai eigen dan vektor eigen

\begin{tabular}{|l|c|r|}
\hline & Nilai eigen maksimal & Vektor eigen \\
\hline Algoritma 1 & 3,002 & $\left(\begin{array}{l}0,233 \\
0,054 \\
0,712\end{array}\right)$ \\
\hline Algoritma 2 & 3,000 & $\left(\begin{array}{l}0,310 \\
0,072 \\
0,948\end{array}\right)$ \\
\hline Algoritma 3 & 3,000 & $\left(\begin{array}{c}0,344 \\
0,106 \\
0,933\end{array}\right)$ \\
\hline
\end{tabular}

\section{KESIMPULAN DAN SARAN}

Perbaikan nilai konsisten matriks keputusan dapat dilakukan melalui kajian elemen baris/kolom matriks keputusan dan relasi preferensi lainnya. Suatu algoritma diusulkan untuk memperbaiki nilai konsistensi matriks keputusan berdasarkan relasi preferensi fuzzy. Secara analitik, kajian ini berdampak pada 
pengembangan dan modifikasi relasi preferensi yang digunakan dalam teori pembauatan keputusan. Secara numerik, kajian ini diarahkan kepada pembuatan komputasi yang relatif mudah.

Pada penelitian yang akan datang, kajian mengenai perbaikan nilai konsisten dapat dianggap sebagai problem-problem optimasi. Hal ini dapat membuka ruang baru dalam pendekatan relasi preferensi dan penerapannya.

\section{DAFTAR PUSTAKA}

Fedrizzi, M. dan Brunelli, M., On the Priority Vector associated with a Reciprocal Relation and a Pairwise Comparison Matrix, Soft Computing, 14 (2010), 639-645.

Herrera-Viedma, E., Herrera, F., Chiclana, F., dan Luque, M., Some Issues of Fuzzy Preferency Relation, European Journal of Operational Research, 154 (2004), 98-109.

Saaty, T.L. dan Vargas, L.G., Models, Methods, Concepts and Applications of the Analytic Hierarchy Process, Springer, 2012

Khabibah, S., Farikhin, dan Puspita, N. K., Pengembangan Metode Tipe AHP berdasarkan relasi Preferensi Fuzzy Tergeneralisir untuk Pembuatan Keputusan Berkelompok, Laporan Penelitian FSM UNDIP, 2015.

$\mathrm{Xu}, \mathrm{Z}$. dan Cuipin, W., A Consistency Improving Method in the Analytic Hierarchy Process, European Journal of Operational Research, 116 (1999), 443-449.

Xu, Z. dan Da, Q., An Approach to Improving Consistency of Fuzzy Preference Matrix, Fuzzy Optimization and Decision Making, 2 (2003), 3-12.

Saaty, T. L., Axiomatic Foundation of the Analityc Hierarchy Process, Management Science, 32 (7) (1986), 841-855.

Tanino, T. Fuzzy Preference Orderings in Group Decision Making, Fuzzy Sets and Systems, 12 (1984), 117-131.

Koczkodaj, W., W., and Orlowski, M., Computing a Consistent Approximation to A Generalized Pairwise Comparison, Computers and Mathematics with Applications, 37 (1999), 79-85. 
